\title{
Intraoral Soft Tissue Fibrosarcoma: A Case Report and Review
}

\author{
1Jagdish Vishnu Tupkari, ${ }^{2}$ Tabita Joy Chettiakandy, ${ }^{3}$ Dimple Padawe, ${ }^{4}$ Keshav Kumar \\ ${ }^{5}$ Manisha Sardar, ${ }^{6}$ Nandita Gupta
}

\begin{abstract}
Adult fibrosarcoma (FS), defined by the World Health Organization as 'malignant neoplasm composed of fibroblasts with variable collagen production and, in classical cases, a 'herringbone' architecture', is a very rare soft tissue sarcoma. The earlier literature revealed that the adult fibrosarcoma was the most commonly occurring lesion, however the incidence of which has declined dramatically over the past several decades. This is due to evolution in the classification of soft tissue tumors, recognition of its subtypes and increased understanding of the many other mesenchymal and nonmesenchymal tumors.

Sarcomas are the rare group of malignancies which accounts for less than $1 \%$ of all the body sarcomas of which 5 to $15 \%$ occurs in head and neck region. It involves deep soft tissues of extremities, trunk, head and neck. Among the head and neck region, intraoral adult fibrosarcomas are very rare without any sex predilection. A case of primary soft tissue FS in posterior mandible of an 13-year-old female patient is documented here, which will be an addition to the cases reported earlier in the literatures.
\end{abstract}

Keywords: Fibrosarcoma, Spindle cell sarcomas, Aggressive fibromatosis, Herringbone, Intraoral.

How to cite this article: Tupkari JV, Chettiakandy TJ, Padawe D, Kumar K, Sardar M, Gupta N. Intraoral Soft Tissue Fibrosarcoma: A Case Report and Review. J Contemp Dent 2014;4(2):118-123.

\section{Source of support: Nil}

\section{Conflict of interest: None}

\section{INTRODUCTION}

Sarcomas are malignant neoplasms originating from mesodermal tissues that constitute connective tissues of the body. ${ }^{1,3}$ They are a rare group of malignancies that represent less than $1 \%$ of body's tumors, including those of the head and neck region., ${ }^{2,3}$ Among these, the fibrosarcoma

\footnotetext{
1,3 Professor and Head, ${ }^{2}$ Associate Professor

${ }^{4,6}$ Postgraduate Student, ${ }^{5}$ Assistant Professor

1,2,4,5 Department of Oral Pathology and Microbiology, Government Dental College and Hospital, Mumbai, Maharashtra, India

${ }^{3}$ Department of Pediatric Dentistry, Government Dental College and Hospital, Mumbai, Maharashtra, India

${ }^{6}$ Department of Oral Medicine, Radiology and Diagnosis, Government Dental College and Hospital, Mumbai, Maharashtra, India

Corresponding Author: Jagdish Vishnu Tupkari, Professor and Head, Department of Oral Pathology and Microbiology, Government Dental College and Hospital, Mumbai, Maharashtra, India Phone: 09820241603, e-mail: jvtupkari@gmail.com
}

(FS) constitutes 5 to $15 \%$ of all sarcomas in the head and neck region. Twenty percent of them arise in the bones and cartilages while $80 \%$ arise in the soft tissues. ${ }^{3}$

\section{CASE REPORT}

A 13-year-old female patient reported to OPD of Government Dental College and Hospital complaining of pain and swelling in lower right posterior region of the oral cavity since 15 days. The swelling had been rapidly increasing in size from a peanut size to approximately $3 \times 4 \mathrm{~cm}$. For this she was put on a course of antibiotics for almost 1 week but there was no regression of the lesion.

Extraoral examination revealed a diffuse tender swelling on the right side of the face. Right submandibular lymph nodes were enlarged, firm and tender on palpation (Fig. 1). On intraoral examination a large well-defined pedunculated growth of size $3 \times 4 \mathrm{~cm}$ was present in the right mandibular posterior region extending antero-posterioly from 46 to 48 involving both the buccal and lingual gingiva. The growth was firm in consistency, nonfluctuant with smooth surface and tender on palpation covering partially 46 and 47 almost completely. The surface of the growth showed areas of indentation and ulceration due to trauma from the opposing teeth. The teeth in the lesional area were firm and nontender on percussion (Fig. 2).

Orthopantomogram (OPG) (Fig. 3) showed an area of ill-defined radiolucency involving the alveolar ridge

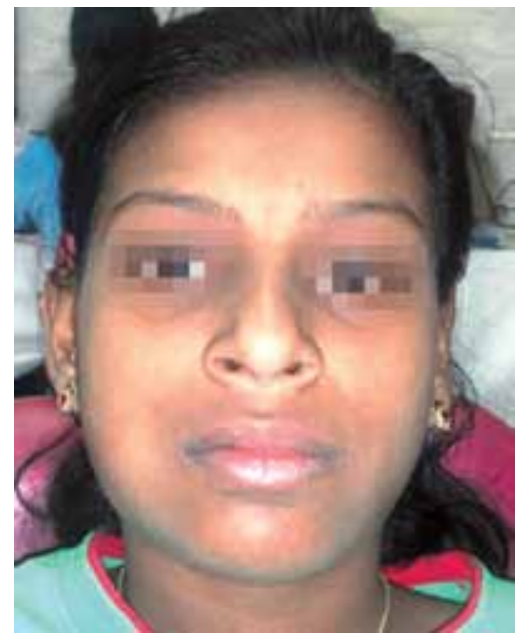

Fig. 1: Nodular swelling present on right side of the face in mandibular region 
extending from the distal root of 46 till mesial root of 47 . Bodily displaced 47 was noted in distal direction. Widening of periodontal ligament space was observed with the distal root of 46 .

Cone beam computed tomography (CBCT) (Fig. 4) showed an area of diffuse radiolucency involving the alveolar ridge extending from the furcation area of 46 till mesial root of 47. The margins of the lesion were ill defined. Thinning, destruction and discontinuity of buccal and lingual cortical plate was noted in certain sections.

Incisional biopsy was performed. Histopathologically, (Figs $5 \mathrm{~A}$ and $\mathrm{B}$ ) scanner view $(\times 4)$ showed proliferative surface epithelium with highly cellular connective tissue stroma and vascular spaces of varying sizes. Low power view $(\times 10)$ showed highly cellular fibrous connective tissue stroma comprising of fibroblast-like cells and collagen fibers arranged in interlacing bands or fascicles that run in different directions showing herringbone pattern. High power view $(\times 40)$ showed proliferation of spindle shaped fibroblast like cells with variable amounts of collagen and reticulin fibers. The cells were uniform spindle-shaped, multipolar, with elongated oval or round hyperchromatic nuclei. Mild pleomorphism and prominent nucleoli were noticed.

The above findings of $\mathrm{H}$ and $\mathrm{E}$ sections were suggestive of fibrosarcoma. Further, immunohistochemistry analysis showed strong reactivity for vimentin, CD-68 and focal reactivity for Ki67, whereas for cytokeratin, S-100 protein, desmin and CD-105, no reactivity were noted (Figs 6A to C). Based on these histopathological observations, a diagnosis of fibrosarcoma was confirmed. Following table depicts the reactivity of various IHC markers in order to differentiate the present case from other spindle cell sarcomas/lesions (Table 1). ${ }^{14,30}$

\section{DISCUSSION}

Fibrosarcoma was defined by Rokitansky (1842) as a tumor with varieties dependent on 'the form and arrangement of fibres.' Various attempt have been made to classify fibrosarcoma under different catagories. Wilks (1849) considered it as fibroblastic whereas Borst (1902) labelled it as fibroma sarcomatosum. Later on Ewing (1940) described fibrosarcoma, spindle-cell sarcoma or fascial sarcoma under the term of neurogenic sarcoma; as he believed that the majority of them are of neurogenic origin. ${ }^{4}$

However, Staut, dismissed the term neurogenic sarcoma, since it has as little meaning as spindle cell sarcoma. He defined fibrosarcoma as 'a tumor composed of spindle shaped fibroblasts and connective tissue fibers which are wrapped around all the cells rather than forming long wire. ${ }^{5}$ In the first, Armed Forces Institute of Pathology (AFIP) fascicle on soft tissue tumor (1953), the term 'non-metastasizing fibrosarcoma' was placed under the heading of fibromatosis, while dermatofibrosarcoma under fibrosarcoma. However, these lesions were removed from these heading in their 2 nd edition (1966). During this time, the concept of the facultative fibroblast (a histiocyte that could appear and function as a fibroblast) had been proposed by Ozzello et al. ${ }^{6,7}$

At one time, (Between 1950 and 1975) fibrosarcoma was the most common soft tissue sarcoma. With the introduc-

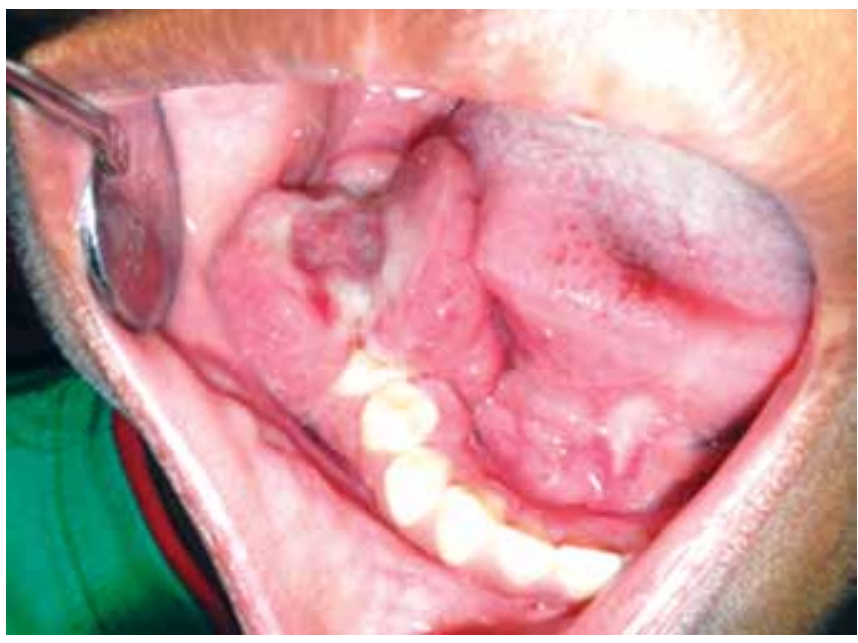

Fig. 2: Pedunculated growth on buccal and lingual gingiva in 46 , 47 regions

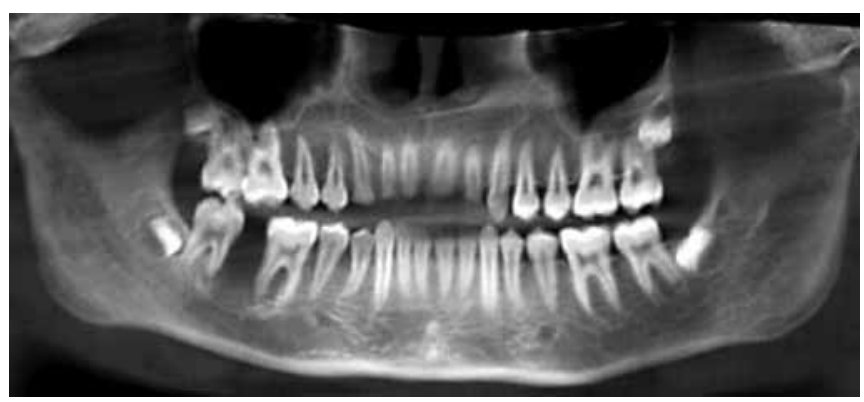

Fig. 3: Orthopantomogram showing alveolar bone loss in 46,47 region with ill-defined margin. Note: Bodily displacement of 47 in distal direction

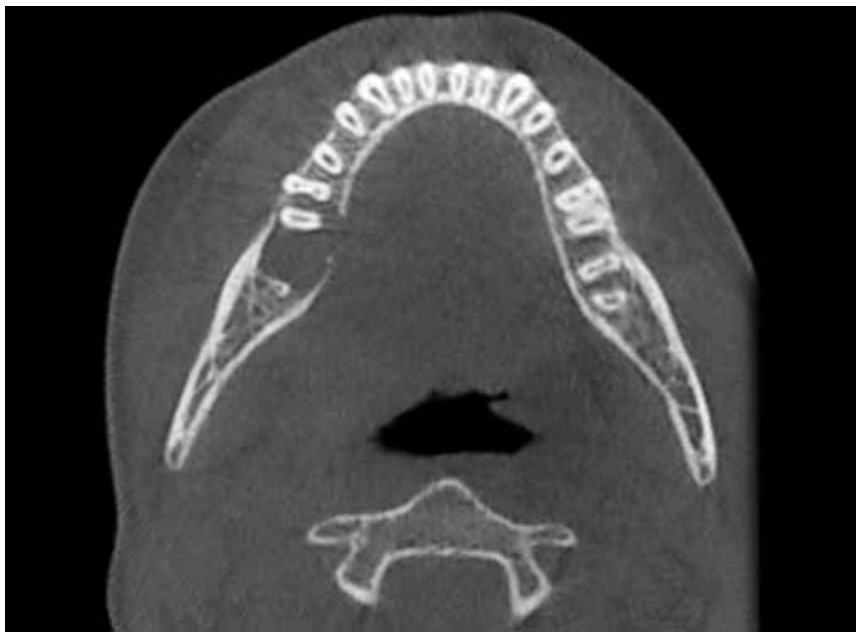

Fig. 4: $C B C T$ showing discontinuity of buccal and lingual cortical plate noted 
tion of electron microscopy and immunohistochemistry, it became evident that many previously diagnosed fibrosarcomas were other spindle cell malignant lesions. ${ }^{8}$ Today, FS is defined as a malignant spindle cell tumor showing a herringbone or interlacing fascicular pattern without expression of other connective tissue cell markers. ${ }^{8-11,13,17,18}$ Kulander and Bolen defined it as 'a neoplasm of fibroblasts capable of producing metastatic spread.' 8,12

Fibrosarcoma may either arise in the soft tissue or of primary intraosseous origin. The latter origin established by Ewing in 1940, and now which has been widely accepted. ${ }^{8,13-15}$ Fibrosarcoma may arise as a primary tumor in any part of the jaws and may be classified as of either central (endosteal) or peripheral (periosteal) type, affecting the bone by spreading from adjacent soft tissue. Secondary fibrosarcoma of the bone may be associated with fibrous dysplasia, Paget's disease, bone infarct or cyst, and/or osteomyelitis. It may also occur as a malignant transformation of giant-cell tumor of the bone or be induced by prior irradiation. ${ }^{16-18}$

Sarcomas are the rare group of malignancies which accounts for less than $1 \%$ of all the body sarcomas of which 5 to $15 \%$ occurs in head and neck region. It involves deep soft tissues of extremities, trunk, head and neck. Among the head and neck region, intraoral adult fibrosarcomas are very
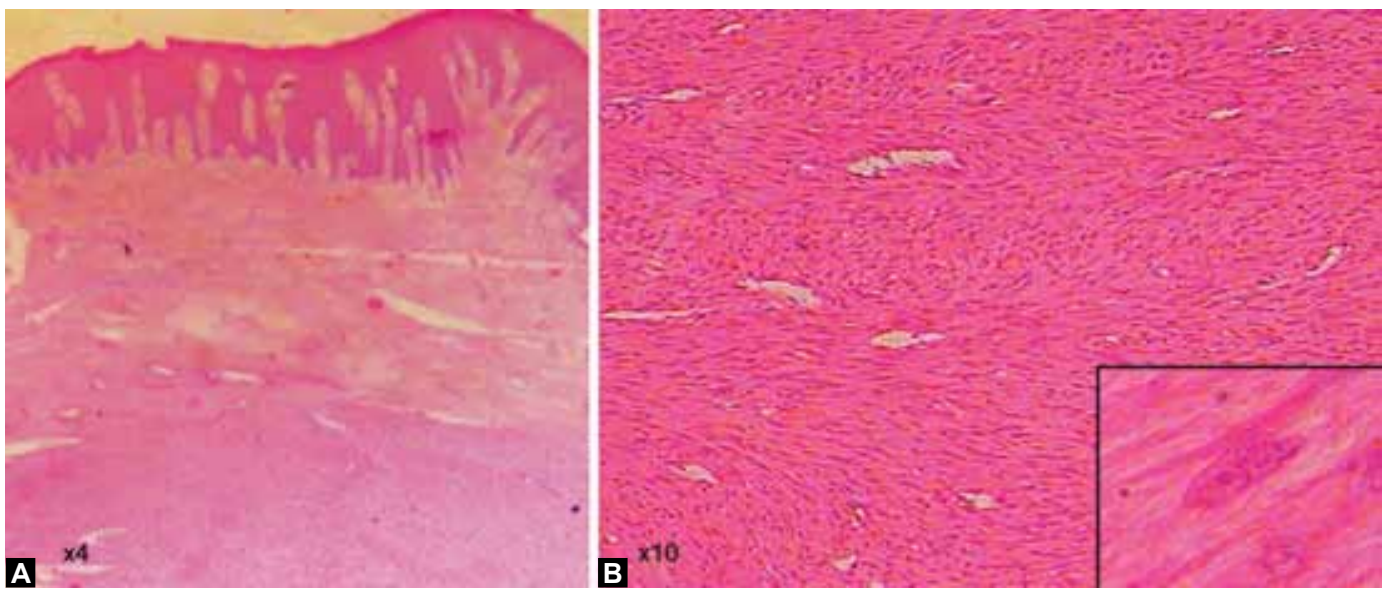

Figs $5 A$ and $B$ : $(A) \times 4$ : Showing deeper lesional tissue with surface epithelium; $(B) \times 10$ : Fibrocellular stroma showing fibroblast like cells with interlacing collagen fiber bundles and herringbone pattern. (inset, $\times 100$ ) Spindle shaped cell with round to oval hyperchromatic nuclei, prominent nucleoli and mild pleomorphism

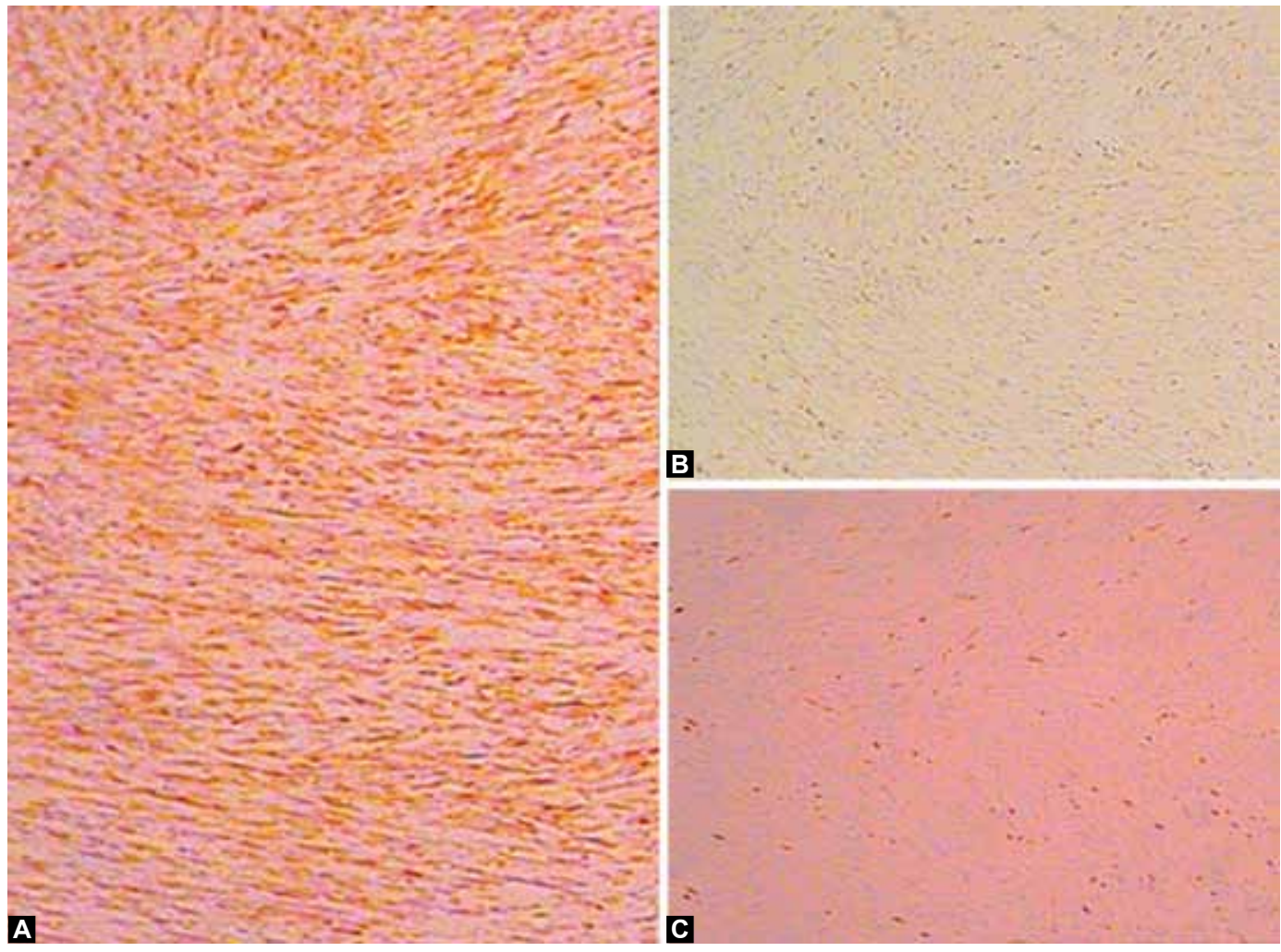

Figs $6 A$ to $C$ : Immunohistochemistry section showing strong reactivity for Vimentin (A), weakly reactivity for MIB I (B) and focal reactivity for CD-68 (C) 


\begin{tabular}{|c|c|c|c|c|c|c|c|}
\hline Lesions $\quad \mathrm{IHC}$ markers & Cytokeratin & $\begin{array}{l}\text { S-100 } \\
\text { Protein }\end{array}$ & Desmin & Vimentin & MIB I & CD-68 & CD-105 \\
\hline Present case (fibrosarcoma) & - & - & - & +++ & Focaly + & + & - \\
\hline $\begin{array}{l}\text { Monophasic fibrous synovial } \\
\text { sarcoma }\end{array}$ & & + & & & & & \\
\hline $\begin{array}{l}\text { Malignant peripheral nerve } \\
\text { sheath tumor }\end{array}$ & & + & & & & & \\
\hline $\begin{array}{l}\text { Desmoplastic malignant } \\
\text { melanoma }\end{array}$ & & + & & & & & \\
\hline Fibromatosis & & & + & & & & \\
\hline
\end{tabular}

rare. ${ }^{3,13-15}$ The soft tissue FS occurs mainly in the subcutaneous, muscular and tendinous tissues. ${ }^{13-15}$

The etiology of fibrosarcoma remains obscure. Although, radiation exposure has been thought to be the most important etiological factor, followed by trauma, and underlying conditions of bone like Paget's disease, fibrous dysplasia, or chronic osteomyelitis. ${ }^{16,17}$ The epidemiological evidence for a causal relation between rabies vaccination and development of fibrosarcoma at the vaccination site in cats also has been made. $^{18}$

A FS in its earlier growth phase often presents as an innocuous nodule. Indeed, it may grow very slowly and progress locally in a fairly indolent form during this earlier phase. However, it may begin to grow rapidly after an inadequate attempt at removal. When this phase is ultimately reached, there are few neoplasms that are more malignant or that will kill with greater certainty. ${ }^{19}$ Clinically, the lesion can cause pain, swelling, paresthesia, and occasionally, losing of teeth and ulceration of the overlying mucosa. ${ }^{20}$

It is more frequent in the fifth and sixth decades of age but cases in children and congenital cases are described in the literature. ${ }^{21-24}$

Because of different clinical behavior and distinctive molecular alterations, infantile fibrosarcoma (IFS) must be considered a separate entity from the identical lesion in adults. Previous literature did not show any unanimous opinion regarding the cut-off age for use of term infantile FS. Different authors have mentioned a cut-off age of 2 years and upto 5 years. ${ }^{25}$

The histological appearance of fibrosarcoma does not allow a distinction between a tumor of the bone from one arising in soft tissue. ${ }^{26}$ Histologically, the degree of differentiation is variable, from being comparable to a benign fibroma to a highly anaplastic tumor, thus presenting a diagnostic dilemma to histopathologists. ${ }^{16}$ Microscopically, there is proliferation of fibroblasts with variable amounts of collagen and reticulin fiber formation. Fibrosarcoma sometimes contains hyalinized collagen that cannot be differentiated from osteoid substance. Characteristically, the cells are uniform spindle-shaped (spindle cell sarcoma), multipolar, with elongated oval or round hyperchromatic nuclei and sometimes may vary little in size and shape. These cells are arranged in interlocking bands or fascicles that run in different directions, and may be arranged in a herringbone pattern or chevron-like with areas of myxomatous, pseudomyxomatous and cartilaginous changes. ${ }^{14,15}$

Its histological grading is based on the degree of cellularity, degree of cellular differentiation, mitotic activity, the amount of collagen produced by the tumor cells and the extent of necrosis. ${ }^{14}$ Fibrosarcoma can be graded as either a low or high grade of malignancy. Low-grade fibrosarcoma shows spindle cells arranged in fascicles with low to moderate cellularity and a herringbone appearance. This type of fibrosarcoma has a mild degree of nuclear pleomorphism, rare mitosis and collagenous stroma. High-grade lesions show an intense nuclear pleomorphism, greater cellularity and atypical mitosis. The nuclei can be spindle shaped, oval or round. The histological appearance of high-grade fibrosarcoma may be similar to other tumors, such as malignant fibrous histiocytoma, liposarcoma or synovial sarcoma. ${ }^{16}$ The French Federation Nationale des Centres de Lutte Contre le Cancer (FNCLCC) grading system is based on the number of mitotic figures, tumor differentiation, and the presence of tumor-necrosis, is recent one, and most widely accepted. ${ }^{27}$

Different histological types of this tumor exist, one of which is myxofibrosarcoma, which was initially described by Angerval in 1977. It is characterized by low cellularity composed of spindle-shaped cells with minimal cytological atypia, and with cells deposited in a variably fibrous and myxoid stroma, usually appearing more myxoid than fibrous. Myxofibrosarcoma has been defined as a malignant fibroblastic lesion in which at least $50 \%$ of the entire tumor displays a highly vascularized and myxoid stroma with distinctive curvilinear vessels. ${ }^{14}$ The positive immunostaining for vimentin, together with negative staining for muscular immunomarkers, helps to diagnose fibrosarcoma. ${ }^{16}$

\section{DIFFERENTIAL DIAGNOSIS}

It is often difficult to distinguish fibrosarcoma from other spindle cells tumors, and in many instances only careful examination of multiple sections and ancillary studies permit 
a correct diagnosis. In bioptic differential diagnosis crucial role is played by immunohistochemical investigation.

Monophasic fibrous synovial sarcoma may also closely simulate FS, although it is generally composed of more ovoid-appearing cells arranged in an irregular fascicular growth pattern. The presence of prominent branching (staghorn) vasculature, distinct focal calcifications, any 'pseudo-osteoid,' or gland or gland-like spaces were identified, then the tumor was excluded as amonophasic synovial sarcoma. ${ }^{28,29}$ Moreover, many of these sarcomas have areas in which the cells contain more eosinophilic cytoplasm with a suggestion of cellular cohesion, even if well-formed glands are not present. Immunohistochemically, almost all cases of synovial sarcoma expressed at least one epithelial marker, such as various cytokeratins, human milk fat globule membrane antigen (HMFG-2) and epithelial membrane antigen (EMA), a feature not found in fibrosarcoma. ${ }^{30,31}$

Aggressive fibromatosis; a non-neoplastic spindle cell proliferation of childhood which may be locally aggressive but has no metastatic potential. It may also show a distinct spindle cell pattern as in FS. The fibromatosis constitute part of a spectrum of poorly understood proliferative lesion whose histologic features overlap to such an extent that the pathologist may be more influenced by the anatomic location of the lesion, sex and clinical behavior than by the histologic appearance in rendering his or her diagnosis. ${ }^{31}$ The fibromatosis that occur in the head and neck including those that involve oral and paraoral structures is considered under the heading of extra-abdominal fibromatosis, infantile fibromatosis is the childhood counterpart of extra-abdominal fibromatosis. ${ }^{31}$ The grade 1 fibrosarcoma is usually discernable from fibromatosis by the presence of occasional larger nuclei with ominous chromatin clumping, greater cellularity, greater mitotic activity and thin rather than thick collagen bundles. ${ }^{28,31}$ Immunohistochemistry can be used as an exclusion criteria to differentiate from sarcomas arising from other mesenchymal tissues. However, it may be of little help in differential diagnosis, from the fibrous connective tissue tumors as positive immunostaining against vimentin can be observed in all of them (Table 1). ${ }^{31}$

The low grade FS shows low to moderate cellularity with often nuclear overlap, nuclear hyperchromasia and more prominent nucleoli as compared to the fibromatosis. Necrosis and vessel formation are rarely seen in low grade fibrosarcoma, which are absent in case of fibromatosis. ${ }^{30}$

The final diagnosis of fibrosarcoma was based on a number of factors which included spindle shaped monotonous population of fibroblasts arranged in a fasciculated pattern, sparse presence of collagen, nuclear overlap, small districts of necrosis and presence of mitotic figures including atypic form. ${ }^{31}$
The treatment of choice is surgical resection with a wide margin. The need for adjuvant radiotherapy and/or chemotherapy is still unclear and is normally indicated in high-grade tumors, because these tumors may present subclinical or microscopic metastases at the time of diagnosis. ${ }^{8}$

Fibrosacroma is a rare malignancy in the oral cavity; local recurrence is frequent, but metastases are rare and spreads by both the local invasion and hematogenous dissemination the commonest site for metastases being the lungs and bones, especially the axial skeleton and rarely to lymph nodes. Metastasis occurs in 9 to $63 \%$ of patients and is time and grade dependent. Five years survival is 39 to $54 \%{ }^{21,22,32,33}$

In our case, the patient underwent hemimandibulectomy on right side with placement of costochondral graft from patient's tibia. The surgery was accomplished at tertiary referral center in October 2013. The patient is under continuous follow-up and no recurrence has been reported so far.

\section{CONCLUSION}

As has been emphasized that, FS is inherently a diagnosis of exclusion, and this diagnosis should be rendered only with the greatest of care, after all other mesenchymal and nonmesenchymal mimics have been excluded through a combination of careful morphological study and ancillary testing. A case of intraoral soft tissue fibrosarcoma with minimal bony involvement and histological grading type 1 (low grade) is reported. The various features that aid in determining the histopathological grading of fibrosarcoma and differentiation from other tumor is emphasized. The role of immunohistochemistry in the present case is evaluated and is found to be of significance in the differentiation of FS from other fibrous connective tissue tumors.

Fibrosarcoma arising within the head and neck region is quite rare, thus it should be included in the differential diagnosis, especially in case of rapidly growing intraoral lesions.

\section{ACKNOWLEDGMENT}

The authors would like to acknowledge the kind support and encouragement of Dr MG Pawar, Dean, Government Dental College and Hospital, Mumbai, India.

\section{REFERENCES}

1. Gorsky M, Epstein JB. Craniofacial osseous and chondromatous sarcomas in British Columbia, a review of 34 cases. Oral Oncology 2000;36(1):27-31.

2. Gorsky M, Epstein JB. Head and neck and intraoral soft tissue sarcomas. Oral Oncology 1998;34(4):292-296.

3. Aljabab AS, Nason RW, Kazi R, Pathak KA. Head and neck soft tissue sarcoma. Ind J Surg Oncol Oct-Dec 2011;2(4):286-290.

4. Quick D, Cutler M. Neurogenic sarcoma: a clinical and pathological study. Ann Surg Dec 1927;86(6):810-829.

5. Staut AP. Fibrosarcoma. The malignant tumor of fibroblast. Cancer 1948;1(1):30-63. 
6. Al-Salihi KA, Al-Jashamy KA, Rahman SA, Samsudin AR. Maxilla tuberosity malignant fibrous histiocytoma with giant fibroblastic cells: case report and review of literature. Oral Oncology Extra 2006;42(3):115-122.

7. Black J, Coffin CM, Dehner LP. Fibrohistiocytic tumors and related neoplasms in children and adolescents. Pediatr Dev Pathol 2012;15(1 Suppl):181-210.

8. Orhan K, et al. Misdiagnosed fibrosarcoma of the mandible mimicking temporomandibular disorder: a rare condition. Oral Surg Oral Med Oral Pathol Oral Radiol Endod 2007;104(4):e26-e29.

9. Neville BW, Damm DD, Allen CM, Bouquot JE. In oral and maxillofacial pathology. 2nd ed. Pennsylvania: WB Saunders Company 2002; p. 480-481.

10. Sapp JP, Eversole LR, Wysocki GP, editors. Contemporary oral and maxillofacial pathology. 2nd ed. St Louis: Mosby 2004; p. 302-303.

11. Regezi JA, Sciubba JJ, Jordan RCK, editors. Oral pathology: clinical pathologic correlations. 4th ed. St Louis: WB Saunders Company 2003; p. 167-168.

12. Kulander BG, Bolen JW. Pathology of soft tissue sarcomas. In: Raaf JH, editor. Soft tissue sarcomas: diagnosis and treatment. St Louis: Mosby 1993 p. 43-68.

13. Soares AB, Lins LHS, Mazedo AP, Neto JSP, Vargas PA. Fibrosarcoma originating in the mandible. Med Oral Pathol Oral Cir Bucal 2006;11(3):e243-246.

14. Angiero F, et al. Fibrosarcoma of the jaws: two cases of primary tumors with intraosseous growth. Anticancer Research 2007;27(4C):2573-2582.

15. Pereira CM, Jorge J, Di Hipolito O, Kowalski LP, Lopes MA. Primary intraosseous fibrosarcoma of jaw. Int J Oral Maxillofac Surg 2005;34(5):579-581.

16. Wadhwan V, Chaudhary MS, Gawande M. Fibrosarcoma of the oral cavity. Indian J Dent Res 2010;21(2):295-298.

17. Yuwanati MB, Tupkari JV. Fibrosarcoma of mandible: a case report; Hindawi Publishing Corporation Case Reports in Dentistry Volume 2011.p.4. Article ID 536086.

18. Patel SG, et al. Soft tissue sarcomas of the head and neck: an update: American J Otolaryngology, $2001 \mathrm{Jan}-\mathrm{Feb}$; 22(1):2-18.

19. Poole N, et al. Soft tissue fibrosarcoma montreal Canada. MAJ 1961 July $1 ; 85$.
20. Stout AP. Tumours of the soft tissues. Atlas of tumour pathology, section Ii, Fascicle 5. Armed Forces Institute of Pathology, Washington, DC 1953.

21. Lukinmaa P, Hietanen J, Swan H, Ylipaavalniemi P, Perkki K. Maxillary fibrosarcoma with extracellular immunocharacterization. Br J Oral Maxillofac Surg 1988;26(1):36-44.

22. Dehne LP, Askin FB. Tumours of fibrous tissue origin in childhood. A clinicopathologic study of cutaneous and soft tissue neoplasms in 66 children. Cancer 1976;38(2):888-900.

23. Dehner LP. Tumors of the mandible and maxilla in children II. A study of 14 primary and secondary malignant tumors. Cancer 1973;32(1):112-120.

24. Blocker S, Koenig J, Ternberg J. Congenital fibrosarcoma. J Pediatr Surg 1987;22(7):665-670.

25. Swain N, Kumar SV, Dhariwal R, Routray S. Primary fibrosarcoma of maxilla in an 8-year-old child: a rare entity. J Oral Maxillofac Pathol 2013 Sep-Dec;17(3):478 doi: 10.4103/0973029X.125226.

26. Chen Y, Wang JM, Li JT. Ameloblastic fibroma: a review of published studies with special reference to its nature and biological behavior. Oral Oncology 2007;43(10):960-969.

27. Fletcher CD, Unni KK, Mertens F, editors. World Health Organization classification of tumours. Pathology and genetics of tumours of soft tissue and bone. Lyon, France: IARC Press; 2002. p. 14.

28. Scott SM, Reiman HM, Pritchard DJ, Ilstrup DM. Soft tissue fibrosarcoma. A clinicopathologic study of 132 cases. Cancer 1989;64(4):925-931.

29. Folpe LA. Fibrosarcoma: a review and update. Histopathology 2014;64(1):12-25.

30. Weiss SW, Goldblum JR. Chapter 11 Fibrosarcoma. In Enzinger and weiss's soft tissue tumors. 5th ed. St Louise, MO, Mosby, 2008:303-338.

31. Adamicova K, et al. Retromolar fibrosarcoma: a diagnostic dilemma case report. Acta Medica Martiniana 2011;11(3):33-38.

32. Shetty DC, Aadithya B, Sikka S. Aggressive fibromatosis versus low grade fibrosarcoma: a diagnostic dilemma. Int J Pathol 2010; 8(1):30-33.

33. Pritchard DJ, Soule EH, Taylor WF, Ivins JC. Fibrosarcoma: a clinicopathologic and statistical study of 199 tumors of the soft tissues of the extremities and trunk. Cancer 1974;33(3):888-897. 